\title{
Hybrid atrial septal defect closure in a child with positional anomaly of the heart and thoracic wall abnormalities
}

\author{
Ireneusz Haponiuk ${ }^{1}$, Maciej Chojnicki², Radosław Jaworski², Mariusz Steffens², Konrad Paczkowski², \\ Katarzyna Gierat-Haponiuk ${ }^{3}$
}

${ }^{1}$ Chair of Physiotherapy, Gdansk University of Physical Education and Sport, Gdansk, Poland

${ }^{2}$ Department of Pediatric Cardiac Surgery, Mikolaj Kopernik Hospital, Gdansk, Poland

${ }^{3}$ Department of Rehabilitation, Medical University of Gdansk, Gdansk, Poland

Postep Kardiol Inter 2015; 11, 3 (41): 246-247

DOI: $10.5114 /$ pwki.2015.54025

We report the case of a successful transatrial hybrid atrial septal defect (ASD II) closure in a borderline 9-month-old girl with multiple congenital defects.

The patient, with hemodynamically significant ASD II, had scoliosis of the thoracic spine with multiple axial skeleton defects, including congenital defects of thoracic vertebrae, defects of the right ribs and agenesis of the sternum (Figure $1 \mathrm{~A}$ ). Moreover, the patient suffered from overflow pulmonary hypertension, associated with hypoplasia of the right lung, hypotrophy with low body weight and height ( $<3$ percentile), and obstructive bronchitis (during pharmacological treatment and permanent nasal oxygen therapy). Intragastric tube feeding was carried out from birth. Despite intensive conventional treatment, the girl had permanent mixed inspiratory-expiratory dyspnea, with signs of central cyanosis, reduction of vesicular murmur on the right side, as well as rales and wheezing.

The echocardiographic examination showed dilatation of the right ventricle (RV), right atrium (RA) and pulmonary artery (PA), paradoxical interventricular septal (IVS) motion, normal size and contractility of the left ventricle (LV), with ASD ॥ (8-10 mm width) in the central area of the septum, with massive left-to-right shunt (Qp : Qs > $2.5: 1$ ), turbulent inflow from pulmonary veins to the left atrium, and elevated systolic pressure of the right ventricle (60-65 $\mathrm{mm} \mathrm{Hg}$ ).

After analysis of the heart defect and hemodynamic effects, with concomitant severe general comorbidities, in the face of clear contraindications to surgery (vascular positional anomalies) as well as to cardiac intervention from peripheral access (small venous diameter), the patient was electively qualified for hybrid transatrial ASD II closure.

The anterior minithoracotomy was made via the $4^{\text {th }}$ intercostal space, where agenesis of the ribs was palpable. The upper lobe of the right lung was naturally expanded, the middle collapsed, and the lower in deep involution. The pericardial sac was opened above the RA in front of the right phrenic nerve. The heart was enlarged and rotated to the left, with enlargement of the RA. A purse string suture was made on the free wall of the RA and the arterial sheath was introduced. The size of the defect was measured in two dimensions using preoperatively transthoracic echocardiography (TTE) and intraoperatively epicardial echocardiography (Figure $1 \mathrm{~B}$ ). Under guidance of transesophageal echocardiography (TEE) and epicardial echocardiography the Amplatzer Septal Occluder 9 mm (AGA, Med. Corp, Minneapolis, USA) was implanted in ASD II. Control epicardial echocardiography showed proper position of the occluder with complete closure of the defect. After removal of the provider and RA decannulation the thoracotomy was closed in layers. The girl was extubated $4 \mathrm{~h}$ postoperatively. Pharmacological treatment of sildenafil and aspirin (for 12 months, as scheduled) was started in the postoperative ward just after the first feeding [1]. In control TTE and chest X-ray the proper position of the implant with complete closure of the shunt was observed (Figures 1 C, D). The decrease of blood pressure in the PA was observed in control echocardiography and successful oral feeding was introduced on the second postoperative day.

The presented hybrid procedure allowed for successful closure of ASD II with reduction to a minimum of the risk of possible complications and adverse effects related

\section{Corresponding author:}

Ireneusz Haponiuk, Department of Pediatric Cardiac Surgery, Mikolaj Kopernik Hospital, 1-6 Nowe Ogrody St, 80-803 Gdansk, Poland, phone: +48 5876404 90, e-mail: ireneusz_haponiuk@poczta.onet.pl

Received: 29.01.2015, accepted: 30.04.2015. 

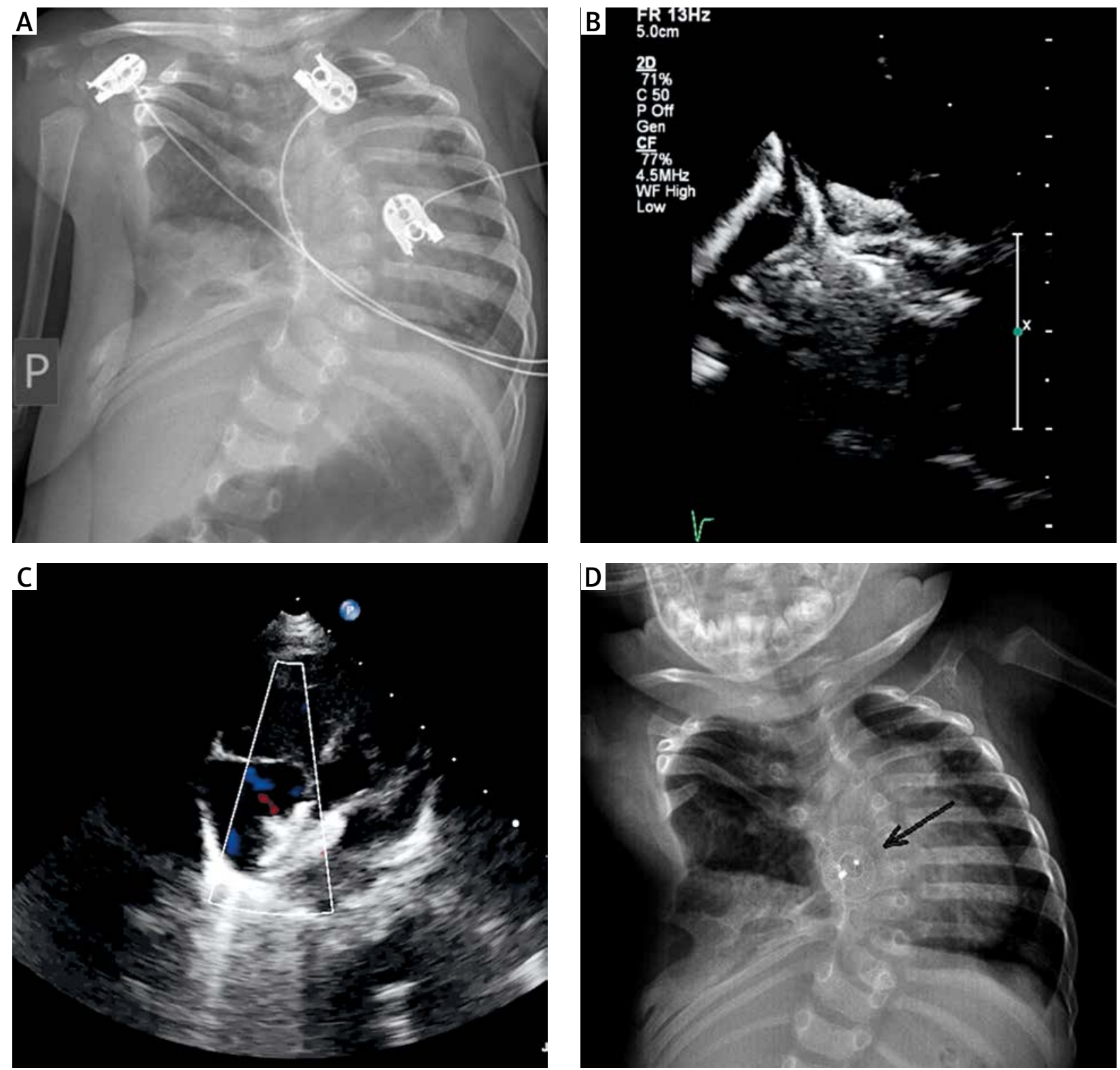

Figure 1. A - Preoperative X-ray: deformation of thorax with scoliosis, agenesis of ribs and sternum and displacement of diaphragm attachment upper to inferior thoracic aperture. B - Intraoperative epicardial echocardiography: provider coming to the left atrium through atrial septal defect (ASD II), via atrium free wall puncture. Right minithoracotomy. C - Control echocardiography (TTE) after hybrid procedure - proper implant position, tight atrial septal defect closure. D - Postoperative X-ray - implant and axial skeleton defects. Improvement of aeration of the right lung

to conventional cardiac surgery in the face of the critical comorbidities [2-4].

\section{Conflict of interest}

The authors declare no conflict of interest.

\section{References}

1. Holzer R, Bolzer D, Cao QL, et al. Device closure of muscular ventricular septal defects with the using Amplatzer Muscular Ventricular septal defect oclluder. JACC 2004; 43: 1257-63.
2. Bacha EA, Hijazi ZM. Hybrid procedures in pediatric cardiac surgery. Semin Thorac Cardiovasc Surg Pediatr Card Surg Annu 2005; 8: 78-85.

3. Haponiuk I, Chojnicki M, Jaworski R, et al. Hybrid cardiovascular procedures in the treatment of selected congenital heart disease in children - a single-centre experience. Kardiol Pol 2014; 72: 223-9.

4. Pedra SF, Jatene M, Pedra CA. Hybrid management of a large atrial septal defect and a patent ductus arteriosus in an infant with chronic lung disease. Ann Pediatr Cardiol 2010; 3: 68-73. 